12 Barker K, Graham NG, Mason MC, De Dombal FT, Goligher JC. The relative significance of preoperative oral antibiotics, mechanical bowel preparations, and preoperative peritoneal contamination in the avoidance of sepsis after radical surgery for ulcerative colitis and Crohn's disease of the large bowel. Br $\mathcal{F}$ Surg 1971;58:270-3.

13 Nichols RL, Broido P, Condon RE, Gorbach SL, Nyhus LM. Effect of preoperative neomycin-erythromycin intestinal preparation on the incidence of infectious complications following colon surgery. Ann Surg 1973;178:453-9.

14 Washington JA II, Dearing WH, Judd ES, Elveback LR. Effect of preoperative antibiotic regimen on development of infection after intestinal surgery: Prospective, randomized, double-blind study. Ann Surg 1974; 180:567-71.

15 Clarke JS, Condon RE, Bartlett JG, et al. Preoperative oral antibiotics reduce septic complications of colon operations: Results of prospective, randomized, double-blind clinical study. Ann Surg 1977;186:251-9.

${ }^{16}$ Nichols RL, Condon RE. Preoperative preparation of the colon. (Collective Review.) Surg Gynecol Obstet 1971;132:323-37.

17 Weinstein WM, Onderdonk AB, Bartlett JG, Louie TJ, Gorbach SL. Antimicrobial therapy of experimental intra-abdominal sepsis. $\mathcal{F}$ Infect Dis $1975 ; 132: 282-6$.

18 Stone HH, Hooper CA, Kolb LD, Geheber CE, Dawkins EJ. Antibiotic prophylaxis in gastric, biliary and colonic surgery. Ann Surg 1976;184: 443-50.

19 Keighley MRB, Crapp AR, Burdon DW, Cooke WT, AlexanderWilliams J. Prophylaxis against anaerobic sepsis in bowel surgery. Br F Surg 1976;63:538-41.

${ }^{20}$ Miles AA, Miles EM, Burke JF. The value and duration of defence reactions of the skin to the primary lodgement of bacteria. Br $\mathcal{F}$ Exp Pathol $1957 ; 38: 79-96$.

21 Burke JF. The effective period of preventive antibiotic action in experimental incisions and dermal lesions. Surgery $1961 ; 50: 161-168$.

${ }^{22}$ Nash AG, Hugh TB. Topical ampicillin and wound infection in colon surgery. Br Med f $1967 ; \mathrm{i}: 471-72$.

${ }^{23}$ Taylor SA, Cawder HM, Smith J. The use of metronidazole in the preparation of the bowel for surgery. Br $\mathcal{F}$ Surg 1979;66:191-92.

24 Anonymous. Antibiotic-associated colitis-a bacterial disease. $\mathrm{Br}$ Med F 1979 ;ii:349-50. *

85 Stewart DJ, Matheson NA. Peritoneal lavage in appendicular peritonitis. Br F Surg 1978;65:54-6.

${ }^{26}$ Stewart DJ, Matheson NA. Peritoneal lavage in faecal peritonitis in the rat. $B r \mathcal{F}$ Surg 1978;65:57-9.

\section{Prostatic cancer: the response to treatment dilemma}

Carcinoma of the prostate is now the second most common cancer in Western men. Its incidence is not increasing but as the population ages more men are living long enough for their prostatic cancer to disseminate, so increasing the contribution made by the disease to the total of deaths from cancer. Much can be done to relieve symptoms, but the prognosis for metastatic prostatic cancer has changed little during the past decade. Several co-operative groups in Europe and the United States are looking for ways to improve the results of treatment, but objective measures are difficult to apply. Resolving this problem of assessment has become urgent with many new treatments now being tested in phase II trials. Such trials, in which only 15 to 25 patients are studied for only a few months, are designed to determine whether a drug seems promising enough for large-scale trials or whether it should be discarded; but decision making is difficult while the criteria of response remain uncertain.

Measures used for assessment rely mostly on measuring metastatic lesions or stabilising progressive disease. Other subjective factors which may be taken into consideration are pain and physical activity, and changes in weight or haemoglobin may also be used as indicators.

Histological and cytological changes in response to endocrine treatment in needle biopsy specimens of the primary cancer should be reliable measures, but their interpretation may be equivocal. Randomised prospective trials comparing two or more treatments of localised disease usually base their results on the metastasis-free interval and the duration of survival. Of these, the first depends, however, on how frequently the patient is surveyed; it may make heavy demands on radiological services and patients may be unwilling to comply repeatedly. Death is an unequivocal end point, but in the absence of necropsy findings the cause may be uncertain. None of these criteria of response is entirely satisfactory.

Prostatic carcinoma commonly metastasises to bone. As seen by conventional radiography bone metastases are often numerous and their size is difficult to measure. The calcification of an osteolytic lesion can be accepted as regression, but usually the lesions are osteoblastic, and, though they become more sclerotic with healing, only their disappearance can be considered as an objective response. Bone metastases may be detected early as areas of increased isotope uptake ("hot spots") on scintigrams, but lesions due, for instance, to Paget's disease may give false-positive results. Little is known of the effect of chemotherapy on isotope uptake, and no method is readily available for quantitating the scans. Lung metastases and soft tissue lesions such as palpable lymph nodes can be measured, but they are not common in this disease and the prognosis is poor when they are present. ${ }^{1}$

Nor is stabilising progressive disease always a satisfactory measure of response. Nearly half of patients with prostatic cancer present with metastatic disease, and progression is often slow. Clearly, therefore, before stability can be accepted as evidence of a response there must have been reliable evidence of progression, and even then assessment depends largely on subjective responses such as relief of pain or nonspecific changes such as gain in weight. Kvols et $a l^{2}$ have attempted to solve this problem by devising a score system to measure factors such as pain, performance status, weight, haemoglobin, and acid phosphatase concentration in assessing new treatments.

Phase II trials can include only patients who have a suitable indicator lesion that can be assessed rapidly. Inevitably such patients constitute a subset whose reactions are not necessarily typical of all those with cancer of the prostate. In randomised trials comparing two or more modalities of treatment known to be effective the full range of objective and non-specific measures, metastasis-free interval, and duration of survival should be taken into account. To add to the difficulties of close monitoring of what may be a slowly evolving disease, the patients' age makes them vulnerable to intercurrent disease and death from other causes, so complicating evaluation even further.

Though the results of clinical and radiological assessment of response are often uncertain, the detailed study of their state at the start of a trial may identify factors that may be important in the stratification of future trials. ${ }^{3}$ There is no specific tumour marker for prostatic cancer. Immunological assays for serum prostatic acid phosphatases provide a more specific assay than biochemical methods, and may perhaps also be more sensitive. ${ }^{4}$ Regular measurement of prostatic acid phosphatases during follow-up may help in drawing attention to the development of bone metastases. Unfortunately, not all patients with metastatic prostatic cancer have raised serum concentrations of acid phosphatase, especially those with anaplastic cancer. ${ }^{5}$ Bone marrow acid phosphatase, when measured by conventional spectrophotometric methods, is an unreliable indicator of metastases ${ }^{6}$; but immunological assays of bone marrow prostatic acid phosphatases seem to be a real aid to diagnosis. ${ }^{7}$ 
The problems are clear enough, but solutions are elusive. Before long research may produce a specific sensitive tumour marker, but meanwhile clinicians must attempt to agree on the best practical criteria of response and adopt them internationally. At present the thread of truth joining many studies has become snared in their disparities.

${ }^{1}$ Paulson DF, Berry WR, Cox EB, Walker A, Laszlo J. Treatment of metastatic endocrine-unresponsive carcinoma of the prostate gland with multiagent chemotherapy: Indicators of response to therapy. $\mathcal{F} \mathrm{Nat}$ Cancer Institute 1979;63:615-22.

${ }^{2}$ Kvols LK, Eagan RT, Myers RP. Evaluation of Melphalan, ICRF-159, and hydroxyurea in metastatic prostate cancer: A preliminary report. Cancer Treatment Reports 1977;61:311-2.

${ }^{3}$ Housepian JA, Byar DP. Carcinoma of prostate. Correlation between radiologic quantitation of metastases and patient survival. Urology $1975 ; 6: 11-6$

${ }^{4}$ Chu TM, Wang MC, Lee C, Killan C, Valenzuela L, Murphy GP. In: Boelsma E, Kroes R, Rümke P, eds. Tumour markers: impact and progress. Amsterdam, Elsevier/North Holland, 1979:25-43.

${ }^{5}$ Merrin C, Etra W, Wajsman Z, Baumgartner G, Murphy G. Chemotherapy of advanced carcinoma of the prostate with 5-fluorouracil, cyclophosphamide and adriamycin. $\mathcal{F}$ Urol 1976;115:86-8.

${ }^{6}$ Pontes JE, Choe B, Rose N, Pierce JM. Reliability of bone marrow acid phosphatase as a parameter of metastatic prostatic cancer. $\mathcal{F}$ Urol 1979;122:178-9.

7 Cooper JF, Foti A, Herschman H. Combined serum and bone marrow radioimmunoassays for prostatic acid phosphatase. $f$ Urol 1979;122: 498-501.

\section{Ventricular defibrillation}

In many hospitals the standard practice is to attempt correction of ventricular fibrillation by direct-current shock with the maximum charge available. For most commercially available defibrillators this is around 400 joules $(\mathrm{J})$. Is this charge adequate? As long ago as 1974 a retrospective study had suggested that body weight might be an important limiting factor in these circumstances and that a defibrillator with a maximum stored energy of only $400 \mathrm{~J}$ would fail to defibrillate $35 \%$ of patients weighing more than $50 \mathrm{~kg} .{ }^{1}$ Experimental evidence also suggested that the electrical threshold required for defibrillation rose in the early stages of myocardial infarction, so that high-energy defibrillators might be particularly important in this clinical setting. ${ }^{2}$ If that view had proved correct it would have increased the cost and size of defibrillators and made them more difficult to handle, as well as presenting possible hazards to the myocardium from high-energy electrical discharge. ${ }^{3}$

An alternative assessment was, however, quickly forthcoming from Pantridge and his colleagues in Belfast, who presented evidence that ventricular fibrillation complicating acute myocardial infarction was usually responsive to lowenergy discharge. ${ }^{45}$ In a prospective study they showed that $42(81 \%)$ of 52 episodes of ventricular fibrillation responded to $100 \mathrm{~J}$ stored energy and that $212(95 \%)$ of 223 episodes were corrected by $200 \mathrm{~J}$. Among a group of patients in whom ventricular fibrillation complicated myocardial infarction within the first hour $98 \%$ of episodes were corrected by $200 \mathrm{~J}$ shocks. Failure to respond to one low-energy shock was often followed by success when the same energy discharge was used a second time. When a low-energy shock failed one of $400 \mathrm{~J}$ was invariably successful. Pantridge et al drew attention to the importance of technique, including the correct positioning and preparation of the electrode paddles; body weight was not a problem in their studies.

There the controversy rested for a while, but further evidence has recently emerged that commercially available defibrillators are adequate. In a retrospective study of 52 patients in whom defibrillation had been attempted during two years 38 patients were successfully defibrillated and 14 were not, despite repeated attempts. ${ }^{6}$ The standard resuscitative procedure was cardioversion with the maximum charge available, which for most of the defibrillators varied from 200 to $400 \mathrm{~J}$. Though those patients in whom defibrillation failed had a higher body weight the difference was not statistically significant. The main difference separating the patients who were successfully defibrillated from their fellows was a mean delay of seven minutes before cardioversion as, opposed to 17 minutes in patients in whom defibrillation failed. Delay was also associated with a higher incidence of acidosis and hypoxaemia among the defibrillation failures. The difficulty of achieving good external cardiac massage and adequate ventilation in the obese was put forward as a possible explanation for failure to defibrillate some of the heaviest patients in the study.

In a recent prospective study ${ }^{7}$ the standard procedure in the presence of ventricular fibrillation was an initial shock of $200 \mathrm{~J}$ stored energy. With this relatively low-energy discharge $75 \%$ of patients were defibrillated at the first shock and $95 \%$ after further shocks as necessary. The success of defibrillation showed no relation to the patients' weight. In contrast to the preceding study, delay before attempted defibrillation was not a deciding factor in determining outcome, though where this could be determined the delays were mostly shorter-around three minutes. The clinical setting of the ventricular fibrillation was, however, critical in determining outcome in those patients with acute myocardial infarction or ischaemia. In the absence of severe hypotension or left ventricular failure successful defibrillation with low-energy shock was the rule, whereas success was less frequent in patients with these complications, which suggest extensive myocardial injury.

No case has been made, therefore, for the development of high-energy defibrillators. Instead the priority should be immediate defibrillation with low-energy shock, minimising delay and so avoiding the steady deterioration in myocardial perfusion that is likely to follow prolonged periods of external cardiac massage and other supportive manoeuvres. In the hospital setting these conclusions provide further justification for nursing patients at high risk in coronary care units, where properly trained nurses can diagnose and defibrillate patients without delay.

1 Tacker WA, Galioto FM, Giuliani E, Geddes LA, McNamara DG. Energy dosage for human transchest electrical ventricular defibrillation. $N$ Engl f Med $1974 ; 290: 214-5$.

2 Tacker WA, Geddes LA, Cabler PS, Moore AG. Electrical threshold for defibrillation of canine ventricles following myocardial infarction. $\mathrm{Am}$ Heart 7 1974;88:476-81.

3 Dahl CF, Ewy GA, Warner ED, Thomas ED. Myocardial necrosis from direct current countershock. Effect of paddle electrode size and time interval between discharges. Circulation 1974;50:956-61.

4 Pantridge JF, Adgey AAJ, Webb SW, Anderson-J. Electrical requirements for ventricular defibrillation. Br Med F 1975;ii:313-5.

${ }^{5}$ Campbell NPS, Webb SW, Adgey AAJ, Pantridge JF. Transthoracic ventricular defibrillation in adults. $\mathrm{Br}$ Med $\mathcal{F} 1977$;ii:1379-81.

6 Gascho JA, Crampton RS, Cherwek ML, Sipes JN, Hunter FP, O'Brien WM. Determinants of ventricular defibrillation in adults. Circulation $1979 ; 60: 231-40$.

7 Kerber RE, Sarnat W. Factors influencing the success of ventricular defibrillation in man. Circulation 1979:60:226-30. 